\title{
Aspectos das orações subordinadas adverbiais em Asurini do Xingu
}

\author{
Aspects of adverbial embedded clauses in Asurini do Xingu
}

Antônia Alves PEREIRA*

Universidade Federal do Pará (UFPA)

\begin{abstract}
RESUMO: Neste trabalho, apresentamos aspectos das orações adverbiais na língua Asurini do Xingu. Mostramos que os recursos utilizados para formar esse tipo de oração nessa língua são a nominalização, acompanhada de $\{-\mathrm{a}\}$, e morfemas subordinadores. Exibimos seis subtipos de orações adverbiais: orações locativas, orações com \{-rame\}, orações com \{ramu\}, orações consecutivas, orações condicionais imaginativas e orações no gerúndio. A codificação dos argumentos nas orações adverbiais depende da valência do verbo e do subtipo verbal: intransitivo ativo ou intransitivo descritivo e no caso desse último subtipo se pertence à classe morfológica $r$ ou $\emptyset$-. As orações adverbiais podem ocorrer antes ou depois da oração principal.
\end{abstract}

PALAVRAS-CHAVE: Oração adverbial. Modo verbal. Morfemas subordinadores. Marcadores de pessoa.

ABSTRACT: In this work, we present aspects of adverbial clauses in the Asurini of Xingu language. We show that nominalization and subordinating morphemes are the resources used for forming this type of clause in the language. Six subtypes of adverbial clause are described: locative clauses, clauses with $\{$-rame $\}$, clauses with $\{\mathrm{ramu}\}$, consecutive clauses, conditional imaginative clauses, and gerundive clauses. The coding of the arguments in the adverbial clauses depends of the valence of the verb and of the verb type: intransitive active or intransitive descriptive, and in the case of the latter subtype of intransitive verb, if it is morphologically belongs to the class $r$ - or $\varnothing-$. Adverbial clauses can occur before or after the main clause.

KEYWORDS: Adverbial clauses. Verbal mood. Subordinate morphemes. Person markers.

\section{Introdução}

Este artigo objetiva apresentar como são formadas as orações adverbiais na língua Asurini do Xingu. Essa língua, conforme classificação de Rodrigues (1986), pertence à família Tupi-Guarani, Tronco Tupi. É falada por aproximadamente 150 índios Asurini que vivem no município de Altamira, estado do Pará. É uma língua de tradição oral, como tantas outras línguas indígenas da América do Sul.

Os dados utilizados aqui foram coletados por nós junto aos seus falantes, em sua aldeia Kwatinemu, no período 2004 a 2011, através de elicitações e textos de natureza variada.

Neste artigo, apresentamos seis subtipos de orações adverbiais no Asurini do Xingu: orações locativas, orações com $\{$-rame\}, orações com $\{$ ramu\}, orações consecutivas, orações condicionais imaginativas e orações no modo gerúndio.

\footnotetext{
* Doutorado em Linguística, docente da Universidade Federal do Pará (UFPA), campus de Altamira, Faculdade de Letras. Altamira - PA - Brasil. Email: antonia@ufpa.br.
} 
Esse artigo está esquematizado da seguinte forma: em (1) apresentamos características das orações adverbiais presentes na tipologia linguística e as características gerais dessas orações na língua Asurini do Xingu, em (2) tratamos dos subtipos de orações adverbiais em Asurini do Xingu, em (3) apresentamos aspectos da ordem das orações adverbiais. Finalmente, apresentamos nossas considerações finais.

\section{Orações subordinadas adverbiais}

A Oração adverbial é aquela que funciona como modificador de VP (verb phrases) ou de uma proposição inteira (ver THOMPSON; LONGACRE, 1985, p. 172).

A tipologia linguística distingue três tipos de orações subordinadas: oração complemento, oração relativa e oração adverbial. A oração complemento "functions as core arguments of a predicate" (NOONAN, 1985, p. 42; DIXON, 2006, p. 3). Conforme Diessel (2005, p. 435), "They are usually obligatory constituents of the main clause and thus cannot be omitted". Já a oração relativa, segundo Dixon (2006, p. 4) "Is part of an NP which fills an argument slot (subject, object, etc.) in a clause. The relative clause modifies the head of the NP (which is generally a noun) and helps to focus on its referent in the same way that others modifiers such as demonstratives and adjectives do".

De acordo com Diessel (2005, p. 435), semanticamente, as orações adverbiais são muito mais específicas que as orações complementos:

While adverbial clauses are marked by adverbial subordinators, which indicate a specific semantic relationship between main and adverbial clauses, complement clauses are often formally unmarked or they include a complementizer, which tends to be semantically much less specific than the subordinator of an adverbial clause (DIESSEL, 2005, p. 435).

Conforme Thompson e Longacre (1985, p. 172), as sentenças adverbiais são marcadas nas línguas do mundo segundo três recursos, a saber: morfemas subordinadores, forma verbal especial e ordem das palavras. Em Asurini do Xingu, esse tipo de sentença é formado por nominalização e por morfemas subordinadores, isto é, morfemas que ocorrem nas formas verbais somente quando estas estão em um dos modos verbais dependentes ${ }^{1}$.

Para Dryer (1992), o subordinador é o responsável pela relação semântica entre a oração adverbial e a oração principal.

Em relação à modalidade, as orações subordinadas adverbiais tendem a vir sobre o escopo de pressuposição, de irrealis e negação dependendo do tipo de subordinação envolvido. O tipo condicional contrafactual falha sobre o escopo modal da negação (cf. GIVÓN, 2001a, p. 311).

Segundo Thompson e Longacre (1985, p. 171): "Just as with adverbs which are single words or phrases, adverbial clauses can be labeled and categorized with respect to the semantic roles they play". Em Asurini do Xingu, um grupo de oração adverbial é classificado conforme o papel semântico que desempenha e outro é rotulado de acordo com o morfema responsável pela subordinação. Assim, classificamos as orações subordinadas adverbiais do Asurini do Xingu em: orações locativas, orações adverbiais com $\left\{\right.$-rame\}, orações com $\{\mathrm{ramu}\}^{2}$, orações consecutivas, orações condicionais imaginativas e orações adverbiais no gerúndio.

\footnotetext{
${ }^{1}$ Sobre os modos verbais dependentes no Asurini do Xingu, ver Pereira (2009).

${ }^{2}$ \{ramu aparece como morfema sufixado à raiz verbal em certos contextos e em outros aparece como partícula.
} 
A codificação dos elementos nas orações adverbiais em Asurini do Xingu, conforme veremos mais adiante, é feita de acordo com a valência dos verbos, levando em consideração a atividade/inatividade dos verbos intransitivos e o fato de o verbo intransitivo pertencer à classe morfológica $\mathrm{r}-$ ou $\emptyset_{-}{ }^{3}$.

Nessa língua, as orações adverbiais condicionam seu verbo ao modo circunstancial, de forma semelhante aos advérbios nas orações independentes, quando antecedem a oração principal e o sujeito dessa oração é codificado por um elemento de terceira pessoa ${ }^{4}$.

As estratégias de formação de oração adverbial no Asurini do Xingu são comuns a outras línguas da família Tupi-Guarani como o Kamaiurá.

\section{Tipos de orações adverbiais}

Conforme Thompson e Longacre (1985), as orações subordinadas adverbiais nas línguas do mundo são divididas em dois tipos básicos: (i) orações subordinadas adverbiais que podem ser substituídas por uma palavra simples. Estão, nesse grupo, as orações adverbiais que exprimem tempo, localização e maneira. Conforme esses autores, nessas orações, "The semantic relationship between the adverbial clause and the main clause is exactly the same as that between the adverbial word and the main clause" (THOMPSON; LONGACRE, 1985, p. 178). E (ii) orações subordinadas adverbiais que não podem ser substituídas por uma palavra simples. Nesse grupo estão aquelas orações adverbiais que expressam propósito, razão, circunstância, simultaneidade, condição, concessão, dentre outras.

Em nossa análise para o Asurini do Xingu, identificamos os dois tipos básicos de orações adverbiais apontados pela tipologia linguística.

A seguir, passamos a tratar dos subtipos de orações subordinadas adverbiais em Asurini do Xingu.

\subsection{Orações adverbiais locativas}

As orações adverbiais locativas indicam a localização ou a direção do evento expresso na oração principal, função análoga à desempenhada pelos locativos em uma sentença simples. Essas orações são marcadas de duas formas no Asurini do Xingu, a saber: (a) Ao verbo é anexado o nominalizador $\left\{\right.$-tap\}, acompanhado pelo morfema $\{-\mathrm{a}\}^{5}$ $\sim\{-\varnothing\}$ e posposição e (b) $O$ verbo é nominalizado pelo morfema $\{-a\} \sim\{-\emptyset\}$ e em seguida recebe o locativo. Os dados abaixo mostram essas duas formas de oração na língua.

$$
\begin{array}{lll}
\text { n-ere-djat-i } & \text { [dje r-ut-av-a } & \text { i] } \\
\text { neg-2sg-vir-neg } & \text { 1sg Rel-voltar-Nom-N } & \text { Posp. } \\
\text { 'você não vem de onde eu estou voltando' } &
\end{array}
$$

\footnotetext{
${ }^{3}$ Esse prefixo antecede o radical de verbo intransitivo descritivo. Possui dois alomorfes: r-, que ocorre antes de vogal, e $\varnothing$, que ocorre antes de consoante.

${ }^{4} \mathrm{O}$ modo circunstancial se realiza no Asurini do Xingu em -i e em $\varnothing$, conforme o verbo termine em consoante ou vogal, respectivamente.

${ }^{5}$ Esse morfema é recorrente nas línguas da família Tupi-Guarani. Em muitas delas ainda marca todas as funções tipicamente nominais. No Asurini do Xingu, dá indícios de ter marcado as funções nominais em estágios anteriores da língua. No estágio atual, parece está perdendo o status gramatical em alguns contextos. Para mais informações sobre esse morfema, remetemos o leitor a Pereira (2009) e Pereira (2011).
} 
(2)

$\begin{array}{lclcc}\text { ere-djauk } & \text { dje } & \text { r-yru } & \text { futuka- } \varnothing \text { ipe }] \\ \text { 2sg-banhar-se } & 1 \text { sg } & \text { Rel-roupa lavar-N } & \text { Loc. } \\ \text { 'Você banhou-se onde (eu) lavo minha roupa' } & \end{array}$

$\begin{array}{lccc}\text { e-apyk } & \text { [je } & \text { pyk-a } & \text { ipe }] \\ \text { 2III-sentar } & 1 \text { sg } & \text { sentar-N } & \text { Loc. } \\ \text { 'sente onde eu estava sentada' } & \end{array}$

As estratégias utilizadas na formação das orações locativas em Asurini do Xingu são similares às estratégias empregadas para formar esse tipo de oração na língua Kamaiurá. Conforme Seki (2000, p. 185), em Kamaiurá, o verbo é nominalizado e marcado no caso locativo ou ocorre como objeto de posposição locativa, vindo, então, sufixado com o morfema $\{-\mathrm{a}\}$.

Em Asurini do Xingu, o sujeito nas orações adverbiais locativas pode ser codificado por zero como em (2) ou por pronomes pessoais como em (1) e (3).

\subsection{Orações adverbiais com \{-rame\}: causa / condição / tempo / explicação}

Em Asurini do Xingu, as orações subordinadas adverbiais com $\{$-rame $\} \sim\{$-ame $\}$ (a forma -rame ocorre depois de vogal e a forma -ame depois de consoante) parecem expressar relações semânticas de causa, de condição, de tempo e de explicação em relação à oração principal.

Até esse estágio de nossa pesquisa, constatamos a presença de uma partícula, ne, que parece, quando aplicada à sentença, restringir sua semântica à expressão de tempo futuro e condição. O exemplo (9), mais adiante, ilustra esse caso. Apesar de essa língua apresentar um conjunto numeroso de diferentes tipos de partículas, não parece fazer uso delas em combinação com esse morfema com a finalidade de distinguir todas as relações semânticas supracitadas. Apenas o morfema $\{$-rame $\}$ e o contexto parecem ser suficientes para distinguir essas relações. É possível que nessa língua as relações causais, temporais, explicativas e condicionais tenham uma semântica similar, assim como em outras línguas. Thompson e Longacre (1985) explicam que, em algumas línguas, as relações de tempo e causa são expressas da mesma forma:

In some languages which simply use a subordinating morpheme like when for time clauses, this morpheme may signal cause as well. It is easy to see why: two events which are mentioned together as being simultaneous or adjacent in time are often inferred to be causally related (THOMPSON; LONGACRE, 1985, p. 181).

Para Givón, (2001b, p. 335) muitas línguas não fazem distinção morfossintática entre orações adverbiais de 'causa' e 'razão'. Semanticamente, as duas orações não são idênticas, porém partilham certos traços: "In most languages, no morpho-syntactic distinction is made between 'cause' and 'reason' clauses. Semantically, one may of course argue that the two are non-identical but rather exhibit a one-way conditional association, so 'cause' is a sub-species of 'reason".

Os dados abaixo ilustram orações adverbiais com $\{$-rame $\} \sim\{$-ame $\}$ :

[kunumĩ avyki-rame] i-‘y - dje-mumy'a

menino apanhar-Subj 3- mãe- refl- envergonhar-se/entristecer-se

'quando/porque/se o menino apanha, sua mãe fica envergonhada/triste' 
As construções com \{-rame\} referem-se a ações habituais, corriqueiras. Os exemplos (5) a (8), abaixo, demonstram isso.

$$
\begin{aligned}
& \text { [ u-py'yk-ame] ga dja'a- } \varnothing \\
& \text { 3II-pegar-Subj } \\
& \text { 'quando/ porque/ se é pego, ele chora' }
\end{aligned}
$$

(6) a. [ga u-py'yk-ame $]$ è dja'a- $\varnothing$

3 sg 3II-pegar-Subj 3sg.Fem chorar-Circ

'quando/porque/se ele a pega, ela chora'

b. [dje u-py'yk-ame] ̃̃ dja'a- $\varnothing$

$1 \mathrm{sg}$ 3II-pegar-Subj 3sg.Fem chorar-Circ

'quando/porque/se eu a pego, ela chora'

(7) [kudjema'e te-py'yk-ame] a-dja'a

homem 1II-pegar-Subj 1-chorar

'quando/porque/se o homem me pega, eu choro'

(8) [u-kyr-ame] i-fu'av-i

3II-dormir-Subj 3-sonhar-Circ

'quando/porque/se dorme, ele sonha'

O exemplo (9) ilustra o tipo de construção com ações que são entendidas como ocorridas no tempo passado, cuja semântica é interpretada como temporal e explicativa.

(9) dje a-dja'a [i-manu-rame]

1sg 1-chorar 3-morrer-Subj

'eu chorei quando/porque ele morreu'

O exemplo (10) ilustra o tipo de construção com ações no futuro, cuja semântica é interpretada como temporal e condicional.

(10) [kudjema'e te-py'yk-ame] a-dja'a ne homem 1II-pegar-Subj 1-chorar Part

'quando/se o homem me pegar, eu chorarei'

A partícula ne, que indica tempo futuro, posicionada no final da oração principal restringe a semântica da oração adverbial à expressão de tempo/condição. A ausência dessa partícula implica que o evento pode ser entendido pragmaticamente como pertencente ao presente ou ao passado.

Seki (2000, p. 193) demonstra que em Kamaiurá a partícula aspecto-temporal rak conduz à interpretação da oração adverbial como sendo de semântica explicativa e causal.

O sujeito da oração adverbial é expresso por nominal em (4), por pronome pessoal em (6a) e em (6b) e por prefixo da série II em (8). O exemplo (11), abaixo, ilustra um sujeito da oração dependente codificado por terceira pessoa especificada.

(11) t-a'yra a-avyki [i-ar-ame]

3-filho 1-bater 3-sair-Subj

'eu bati no filho dele quando ele saiu' 
A marcação de pessoa que aparece no verbo transitivo das orações adverbiais acima (série II dos prefixos) é marca de concordância com o sujeito da oração principal.

\subsection{Orações adverbiais com \{ramu\}: temporal / condicional}

As orações subordinadas adverbiais com $\{$ ramu $\} \sim\{a m u\}$ (a forma $\{$ ramu $\}$ ocorre depois de vogal e a forma $\{\mathrm{amu}\}$ depois de consoante) anexado ao verbo expressam tempo ou condição da realização de eventos previstos na oração principal. Nos dados abaixo, $\{$ ramu $\}$ funciona como uma marca de condicional:

(12) maja u-djuka [u-furu-mamak-amu ]

cobra 3-matar 3II-Gn-morder-Cond

'ele mata a cobra quando/se ela morder (gente)'

Ao que parece, as orações adverbiais com $\{$ ramu $\}$ diferenciam-se semanticamente das orações adverbiais com \{-rame\} pelo fato de estas se referirem a eventos reais, costumeiros, habituais ao passo que as adverbiais com $\{$ ramu $\}$ preveem a realização do evento da oração principal se/quando o que é referido nela acontecer. Ao contrário dos eventos expressos nas orações com \{-rame\}, os eventos previstos nas orações com $\{\mathrm{ramu}\}$ não são habituais, 'reais', mesmo que previsíveis. Há, dessa forma, uma aproximação semântica entre os dois tipos de oração: ambas se referem ao tempo e à condição de realização de um evento. O exemplo (12), acima, e o (13), abaixo, ilustram o que colocamos.

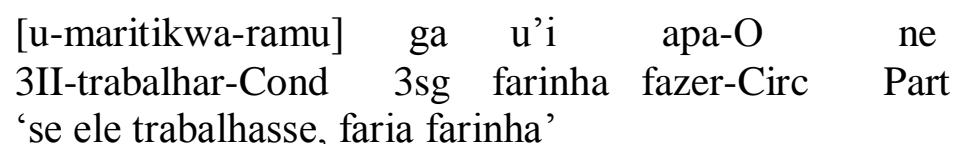

'se ele trabalhasse, faria farinha'

A partícula ne, além de ressaltar o tempo futuro na sentença, parece restringir a semântica da oração adverbial à expressão de condição. O exemplo (14), abaixo, ilustra o que dissemos.

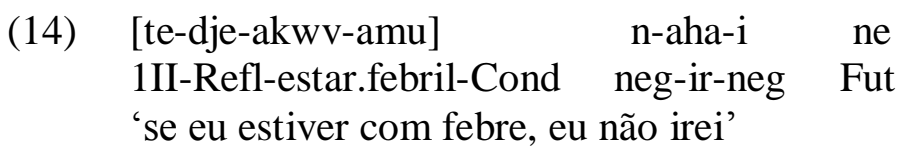

A codificação do sujeito na oração adverbial com $\{$ ramu $\}$ é marcada das seguintes formas: a) por prefixos da série II, exemplo (13) acima e b) por zero quando o sujeito da oração adverbial é co-referente com o sujeito da oração principal exemplo (15) abaixo.

[ipira py'yk-amu] a-mana ene ve
peixe pegar-Cond 1-dar 2sg Posp
'quando/se eu pegar peixe, darei a você'

\subsection{Condicionais imaginativas}

As condicionais imaginativas ou "unreality conditionals", conforme Thompson e Longacre (1985, p. 191), são usadas para situações condicionais irreais, isto é, para aquelas situações que imaginamos que poderia ser ou poderia ter sido. Esse pensamento é encontrado também em Givón (2001b, p. 331) 
Irrealis conditional clauses fall under the scope of non-fact modality. Much like irrealis clauses elsewhere, they thus have no truth value. Rather, their truth value depends on the truth of their associated main clause -which most typically is also under irrealis scope and thus has no truth value either (GIVÓN, 2001b, p. 331).

Na marcação de modo de cláusulas adverbiais irrealis, segundo Givón (2001a p. 324), a diferença entre a marcação subjuntiva e a marcação contrafactual pode ser feita por forma subjuntiva vs não-subjuntiva, por formas modais diferentes ou por marcação irrealis diferente na cláusula principal.

No Asurini do Xingu, as condicionais imaginativas são marcadas com \{-rame\}, subjuntivo e $\{$ ramu $\}$, condicional, simultaneamente.

$\begin{array}{lcccc}\text { [djawara } & \text { ga } & \text { 'u-rame-amu } & \text { djawara } & \text { a-djuka } \\ \text { cachorro } & \text { 3sg.Mas } & \text { morder - Subj-Cond } & \text { cachorro } & \text { 1-matar } \\ \text { 'se o cachorro o mordesse, eu o mataria (o cachorro)' }\end{array}$

(17) [dje marakajĩg-ame-amu ga kyr-i

$1 \mathrm{sg}$ cantar-Subj-Cond 3sg dormir-Circ

'se eu cantasse, ele dormiria'

(18) [jĩ kuj-ame-amu $]$ kujĩ kawĩ apa castanha cair-Subj-Cond mulher mingau fazer 'se caísse castanha, a mulher faria mingau'

Como podemos observar nos exemplos acima, os eventos expressos nesse tipo de oração adverbial são hipotéticos e os que ocorrem na oração principal são condicionados a eles. A codificação do sujeito, nesse tipo de oração adverbial, é feita por nominal (16) e (18) e por pronome pessoal (17).

\subsection{Orações adverbiais temporais consecutivas}

As orações adverbiais temporais consecutivas caracterizam-se pelo emprego do sufixo $\{\text {-rire }\}^{6}$, marcador de modo verbal consecutivo, imediatamente após o radical verbal da oração dependente. Esse tipo de oração indica que o evento expresso nela é anterior ao expresso na oração principal, como podemos ver nas ocorrências (19) a (21).

(19) [mani'aka dje pepin-ire] u'i a-apa mandioca 1sg descascar-Cons farinha 1-fazer 'depois de descascar mandioca, eu faço a farinha'

(20) a-kyt futat [dje karu-rire]

1-dormir querer 1 sg comer-Cons

'depois de comer, eu quero dormir'

(21) [djane karu-rire] txa-kyt futat 1pl karu-Cons 1Pl-dormir querer 'depois de comer, nós queremos dormir'

\footnotetext{
${ }^{6}$ Esse morfema adquire a forma $\{$-ire $\}$ quando aparece depois de consoante.
} 
As orações consecutivas, quando ocorrem antes da oração principal, condicionam o verbo dessa oração ao modo circunstancial, como no exemplo (22) abaixo:

$$
\begin{aligned}
& \text { [ure dje'ẽga rire] ẽ vaem-i } \\
& \text { 1pl fala Cons 3sg.Fem chegar-Circ } \\
& \text { 'ela chegou depois de nossa fala' }
\end{aligned}
$$

\subsection{Orações adverbiais no gerúndio}

A oração subordinada adverbial marcada no gerúndio expressa semanticamente modo e finalidade da oração principal. Os eventos da oração no gerúndio podem ocorrer simultânea ou posteriormente aos eventos da oração principal.

As orações abaixo ilustram modo no exemplo (23) e finalidade no exemplo (24). Em relação ao tempo de ocorrência dos eventos, o exemplo (24) ilustra o evento da oração adverbial no gerúndio ocorrendo depois do evento principal, os exemplos (23) e (25) ilustram o evento da oração principal ocorrendo ao mesmo tempo do evento da oração adverbial.

(23) kunumi-mer-a ipira [u-py'yk ut-a] menino-Pl-N peixe 3-pegar vir-G

'os meninos vieram pegando peixe'

(24) je a-em [te-je- pytuekyt-a]

1sg 1-ausentar 1II-Refl-respirar-G

'eu me ausentei para respirar'

(25) ene ere-aha [tamudje'ẽng-a]

2sg 2-ir assoviar-G

'você saiu assoviando'

A oração adverbial marcada com gerúndio, no Asurini do Xingu, partilha vários traços com esse tipo de oração em Kamaiurá, dentre eles a forma de subordinação.

As orações no gerúndio caracterizam-se por apresentar uma série de propriedades que as distinguem dos outros tipos de orações dependentes. Essas propriedades são tratadas ao longo dessa sessão. O modo gerúndio é marcado em Asurini do Xingu das seguintes formas:

$\begin{array}{ll}\mathbf{- a} & \text { depois de consoante } \\ \mathbf{- w} & \text { depois de vogal oral } \\ \mathbf{- \mathbf { w }} & \text { depois de vogal nasal }\end{array}$

Esse tipo de oração adverbial partilha o mesmo sujeito com a oração principal e os eventos nelas expressos exprimem sucessividade, conforme se pode conferir nos exemplos abaixo:

(26) a. pedje t-yru pe-futuka [pedje-marakaĩĩg-a]

2pl 3-roupa 2Pl-lavar 2plII-cantar-G

'vocês lavam a roupa de vocês cantando' 
b. [te-ata-w] je $\varnothing$-memyra a-raha

1II-caçar-G 1sg Rel-filho 1-levar

'quando vou caçar, levo meu filho'

Lit:/caçando, levo meu filho/

A codificação dos argumentos nesse tipo de oração é guiada pela valência do verbo e pela subclasse de verbos intransitivos. $\mathrm{O}$ argumento de verbos intransitivo ativo e intransitivo descritivo da classe $\varnothing$ é codificado por prefixo pessoal da série II. Os exemplos (27), (28) e (29) abaixo ilustram o que dissemos.

(27) dje dji a-imẽ'e [te-djat-a]

1sg machado 1-amolar 1II-vir-G

'eu amolei o machado para vir'

(28) dje a-djat [te-furaat-a]

1sg 1-vir 1II-dançar-G

'Eu vim dançar'

(29) [dje te-marin-a] a-erut djĩn

1 sg 1II- estar.doente-G 1-vir correr

'eu vim correndo (estando) doente'

Quando a oração no gerúndio é construída com verbos intransitivos descritivos que começam por vogal ou pertencentes à classe r-, a codificação do sujeito é feita por pronome pessoal, acompanhado de prefixo relacional, semelhantemente à codificação do possuidor nas locuções possessivas.

(30) [ene r-akuv-a] ere-djat

2sg Rel-febril-G 2-vir

'você veio (estando) febril'

A codificação de So, quando este é uma terceira pessoa, é feita pelo prefixo que representa a terceira pessoa reflexiva $\{-\mathrm{u}\}$.

(31) ga u- ut [u-dje-apẽ'ẽ- $\tilde{w}]$

3sg 3-vir 3-refl-esquentar-G

'Ele veio para se esquentar'

Os sujeitos de verbo transitivo na oração adverbial no gerúndio podem ser codificados por zero. Os exemplos (32), (33) e (34) abaixo demonstram isso.

(32) myra u-ut [anyra djuka-w]

Npr 3-vir morcego matar-G

'myra veio matar o morcego'

(33) yvyra'a a-py’yk [etũn-a]

fruta 1-pegar cheirar-G

'peguei fruta para cheirar' 


\section{(34) kunumi u-dja'a ['at-a]}

menino 3-chorar cair-G

'o menino chorou quando caiu

O objeto de verbos transitivos da oração no gerúndio é codificado das seguintes formas: a) quando representa primeira ou segunda pessoa, é codificado por pronome pessoal, seguido de prefixo relacional, analogamente à codificação dos sujeitos de verbos intransitivos descritivos (exemplo 35) e b) é codificado por prefixo relacional $\{\mathrm{i}-\}$ ou nominal quando representa terceira pessoa (exemplos 36, abaixo, e 32, acima, respectivamente).

$$
\begin{aligned}
& \text { dje a-djat [ene r-etxak-a] } \\
& 1 \text { sg 1-vir 2sg Rel-ver-G } \\
& \text { 'eu vim para te ver' }
\end{aligned}
$$

$$
\begin{array}{llll}
\text { ga ipira } & \text { u-py’yk } & \text { [i-mukaẽ- } \tilde{w}] \text { i-'u } \\
\text { 3sg peixe } & \text { 3-pegar } & \text { 3-abocanhar-G } & \text { 3-comer } \\
\text { 'ele pegou o peixe, abocanhando-o comeu-o' }
\end{array}
$$

Quando a oração adverbial no gerúndio aparece antes da oração principal e o sujeito dessa última oração está na terceira pessoa, o verbo da principal fica no modo circunstancial, o que serve para reforçar o caráter adverbial da oração marcada no gerúndio. $\mathrm{O}$ exemplo abaixo ilustra essa situação:

$$
\begin{array}{lllr}
\text { [t-yru } & \text { u-futuka-w] } & \text { e } & \text { marakajĩg-i } \\
\text { 3-roupa } & \text { 3-lavar-G } & \text { 3sg } & \text { cantar-Circ }
\end{array}
$$

'(ela) lava roupa cantando'

As orações no modo gerúndio são negadas com o morfema $\{-\mathrm{e}$ ỹma $\}$, sufixado à forma verbal. Segue um exemplo abaixo:

$$
\begin{aligned}
& \text { ga u-ut [u- marakajĩg-a-e'ỹma] } \\
& \text { 3sg } 3 \text {-vir } \quad \text { 3II-cantar-G- neg } \\
& \text { 'ele veio não para cantar' }
\end{aligned}
$$

Como vemos, a negação da oração no gerúndio atinge somente o evento que é encerrado nela. A negação da oração principal da mesma forma que a negação da oração no gerúndio atinge apenas o evento que é encerrado nela, não se estendendo a outra oração. Abaixo um exemplo de negação na oração principal em um período composto por oração principal mais oração no gerúndio.

$$
\begin{array}{llcl}
\text { ipira } & \text { n-u-vevuj-i } & \text { [u-aja } & \text { mukue-w } \\
\text { peixe } & \text { neg-3-nadar-neg } & \text { 3-cauda } & \text { balançar-G } \\
\text { 'o peixe não nadou balançando a cauda' }
\end{array}
$$

\section{Nota sobre a ordem das orações adverbiais em relação à principal}

Em Asurini do Xingu, a oração adverbial pode aparecer à direita ou à esquerda da oração principal assim como os advérbios podem aparecer no início ou no fim da oração. Os exemplos exibidos ao longo deste trabalho demonstram essas afirmações. 
Conforme Diessel (2005, p. 442), as línguas de ordem OV, que é o caso do Asurini do Xingu, tendem à colocação da oração adverbial anteposta à oração principal: "All of the languages in which adverbial clauses tend to precede the main clause/predicate are $O V$ languages in my sample. However, languages in which adverbial clauses are commonly pre-and postposed to the main clause/predicate are more diverse in this regard".

Schaub (1985, p. 37) mostra que em Banbungo a ordem da oração adverbial em relação à principal depende do tipo de oração adverbial:

The position of adverbial clauses depends on the type of adverbial clause. There is only one type which obligatorily precedes the superordinate clause: the conditional clause. Two types, i.e. time clause and restrictive clause, may precede or follow the superordinate clause, although the time clause usually follows it. All other types, i.e. manner clause, cause clause, result clause, equative clause and circumstantive clause have to follow the superordinate clause (SCHAUB, 1985, p. 37) .

Givón (2001b, p. 33), em consonância com Thompson e Longacre (1985), mostra que há mudança de escopo nas orações de propósito conforme se encontrem antes ou depois da oração principal: "Pos-posed purpose clauses most typically code the intent of the main-clause agent in performing his/her action. Pre-posed purpose clauses typically have a broader, more diffuse scope, not necessarily referring to the main-clause agent's purpose".

Para Thompson e Longacre (1985), as orações adverbiais antepostas à principal têm uma função textual de alcance mais amplo que as pospostas. As antepostas remetem a todo o parágrafo anterior, enquanto que as pospostas se referem somente à cláusula principal, sendo assim de alcance mais localizado.

Em Português, língua de ordem VO/SV, as orações adverbiais podem aparecer antes ou depois da oração principal, sendo que as posições distintas afetam a focalização dos eventos. Quando o falante quer focalizar o evento expresso na oração adverbial, esta aparece antes da principal; já se o evento focalizado é o que se encontra na oração principal, esta antecederá a oração adverbial.

\section{Considerações finais}

Neste trabalho, interessamo-nos por aspectos das orações adverbiais no Asurini do Xingu. Analisamos seis subtipos de orações adverbiais que se diferenciam quanto à semântica, à morfologia e à sintaxe. Os recursos utilizados para a formação dessas sentenças, na língua, são morfemas subordinadores e nominalização.

Ficou evidenciado ao longo desse artigo que a oração subordinada adverbial em Asurini do Xingu tem vários traços em comum com a língua Kamaiurá, conforme a análise de Seki (2000) para a língua.

Mostramos que a seleção de argumento subjetivo nas orações adverbiais é feita de acordo com a valência do verbo e de acordo com os subtipos verbais intransitivo ativo e intransitivo descritivo e, no caso desse último subtipo, a seleção ainda leva em consideração o fato de o verbo pertencer à classe morfológica r- ou $\emptyset$.

Será gratificante para nós, se esse trabalho puder contribuir para estudos tipológicos e/ou histórico-comparativos envolvendo línguas da família tupi-guarani e do tronco tupi. 


\title{
REFERÊNCIAS
}

DIESSEL, H. The Ordering Distribution of Main and Adverbial Clauses: A typological study. Language, v. 77, n. 3, p. 433-455, 2005.

DIXON, R. M. W. Complement clause and complementation strategies in typological perspective. In: DIXON, R. M. W. e AIKHENVALD, A. Y. (Ed.). Complementation: a cross-linguistic typology. Oxford: OUP, 2006. p. 1-48.

DRYER, M. S. Adverbial subordinators and word order asymmetries. In: JOHN A. H.; SIEWIERSKA, A. (Ed.). Performance principles of word order. Eurotype Working Papers. Strasbourg: European Science Foundation Program in Language Typology, ESF Office, 1992. p. 1-33.

GIVÓN, T. Syntax: a functional-typological introduction. Amsterdam/Philadelphia: John Benjamins, 2001a. v. 1.

GIVÓN, T. Syntax: a functional-typological introduction. Amsterdam/Philadelphia: John Benjamins, 2001b. v. 2.

NOONAM, M. Complementacion. In: SHOPEN, T. (Ed). Language typology and syntactic description. Cambridge: Cambridge University Press. 1985, v. 2, p. 42-140.

PEREIRA, A. A. Classes de palavras em Asurini do Xingu: o nome In: III CIELLA: Estudos Linguísticos e Literários: Histórias e Perspectivas, vol. 1. Belém. 2011, p. 84-92.

PEREIRA, A. A. Estudo Morfossintático do Asurini do Xingu. Tese (Doutorado) Universidade Estadual de Campinas. Campinas, SP, 2009.

RODRIGUES, A. D. Línguas Brasileiras: para o conhecimento das línguas indígenas. São Paulo: Loiola, 1986.

SCHAUB, W. Babungo. Londres: Croom Helm, 1985.

SEKI, L. Gramática do Kamaiurá: Lingua tupi-guarani do Alto Xingu. Campinas, SP: Editora da Unicamp; São Paulo: Imprensa Oficial, 2000.

THOMPSON, S. A.; LONGACRE, R. E. Adverbial clauses. In: SHOPEN, T. (ed). Language typology and syntactic description. Cambridge: Cambridge University Press. 1985, v. 2, p. 171-234.

\begin{abstract}
Abreviaturas
Cond $=$ Condicional, Circ $=$ Modo circunstancial, Cons=Modo consecutivo, Fem=Falante de sexo feminino, Fut=Tempo futuro, $\mathrm{G}=$ Modo gerúndio, $\mathrm{Gn}=$ Morfema genérico, Loc=Locativo, Mas=Falante de sexo masculino, Subj=Modo subjuntivo, Nom=Nominalizador, $\mathrm{N}=$ Nominalizador de argumento nuclear, Neg=Negação, $\mathrm{Npr}=$ Nome próprio, Part.=Partícula, Pl=Plural, Posp=Posposição, Refl=Reflexivo, Rel=Prefixo relacional, $\mathrm{S}=$ Sujeito de verbo transitivo, $\mathrm{Sa}=$ Sujeito de verbo transitivo ativo, So $=$ Sujeito de verbo transitivo descritivo, $1=1^{\mathrm{a}}$ pessoa, $2=2^{\mathrm{a}}$ pessoa, $3=3^{\mathrm{a}}$ pessoa.
\end{abstract}

Recebido em outubro de 2011.

Aprovado em novembro de 2012. 